\title{
Multidose optimization simulation of erythropoietin treatment in preterm infants
}

\author{
Matthew R. Rosebraugh ${ }^{1}$, John A. Widness ${ }^{2}$ and Peter Veng-Pedersen ${ }^{1}$
}

INTRODUCTION: Preterm infants commonly develop anemia requiring red blood cell transfusions (RBCTx). Although an alternative therapy is recombinant human erythropoietin (Epo), it is not widely employed. To provide a rigorous scientific basis supporting the latter approach, a model-based simulation analysis of endogenous erythropoiesis was developed.

RESULTS: The pharmacodynamic/pharmacokinetic (PK/PD) model identified an optimal Epo dosing algorithm in preterm infants that demonstrated maximal efficacy when Epo was dosed frequently during the early weeks of life (when phlebotomy loss is greatest). Model-based simulations employing optimized Epo dosing predicted that 13 of the 27 (46\%) infants would avoid RBCTx ("good responders"). Importantly, simulation results identified five subject-specific covariate factors predictive of good Epo response.

DISCUSSION: This simulation study provides a basis for possibly eliminating RBCTx in infants who can be selected for optimized Epo therapy.

METHODS: Epo PD hemoglobin production parameters were determined in 27 preterm infants studied intensively during the first $28 \mathrm{~d}$ of life. Model-derived Epo PD parameters were combined with PK parameters derived from the literature to simulate an optimized intravenous Epo bolus dosing schedule. The goal of this simulated optimized schedule was to eliminate RBCTx, as prescribed per current guidelines, in as many preterm infants as possible.

A 11 preterm infants develop anemia in the first few weeks of life as a result of multiple physiologic, pathophysiologic, and iatrogenic events (1). Among neonates most critically ill, anemia is greatly exacerbated by frequent physician-ordered laboratory tests (2-4). As treatment for anemia, as many as $80 \%$ of very-low-birth-weight infants (VLBW) (weighing less than 1,500 $\mathrm{g}$ at birth) and $95 \%$ of extremely-low-birth-weight infants (weighing less than $1,000 \mathrm{~g}$ at birth) receive one or more red blood cell transfusions (RBCTx (5)). The efficacy of RBCTx, measured in terms of improving tissue oxygenation, is not always apparent. Moreover, RBCTx as given to preterm infants are expensive and can be associated with complications that include microbial infections, retinopathy of prematurity, and electrolyte perturbations (6).
The hormone erythropoietin (Epo) stimulates red blood cell (RBC) production and has been investigated as an alternative therapy for the treatment and prevention of neonatal anemia. A meta-analysis of 27 Epo clinical trials in VLBW and extremely-low-birth-weight infants in which the goal was to reduce RBCTx concluded that the effect of Epo in reducing RBCTx in preterm infants was too limited to be of clinical importance (6). However, this conclusion may be challenged for several reasons. First, there are difficulties in combining many clinical trials into a meta-analysis because of the heterogeneity of studies employing different Epo doses and schedules, different routes of Epo administration, different RBCTx criteria, different definitions of success, and different enrollment criteria. Second, the empirical choice of dosing used in some Epo clinical trials is limited because the trials were not designed to recognize the individual responsiveness to Epo treatment (different pharmacodynamics (PD)).

An attractive alternative approach to the design of Epo clinical trials in preterm infants is a personalized medicine approach in which Epo's complex pharmacokinetics (PK) and PD are more fully considered. This powerful PK/PD approach is attractive because it considers how individual infants respond to Epo. Thus, this approach can be used to develop an optimized Epo dosing regimen that both (a) targets subsets of infants predicted to be the most responsive to treatment with Epo and (b) identifies those unlikely to respond. Unfortunately, compared with the extensive Epo PK/PD studies in adults, only limited Epo $\mathrm{PK} / \mathrm{PD}$ data exist in this difficult-to-study infant patient group.

The mechanism of action for the clearance of Epo in both adults and infants has been identified as nonlinear, Epo receptor (EpoR)-mediated endocytosis (5,7-9) followed by lysosomal degradation(10). Determining preterm infants' $\mathrm{PD}$ response to Epo is experimentally demanding because it requires an accurate, real-time evaluation of hemoglobin $(\mathrm{Hb})$ production, a procedure that is greatly impacted by the numerous phlebotomies and RBCTx very premature infants receive (1). Recently, our research group overcame these problems using a mass balance approach to determine $\mathrm{Hb}$ production in 14 critically ill VLBW preterm infants studied for factors impacting endogenous erythropoiesis. This approach required meticulous accounting for $\mathrm{Hb}$ transfused and $\mathrm{Hb}$ removed 
by phlebotomy for RBC losses caused by senescence and for expanding blood volume as a consequence of growth (11).

The sample size was not specifically determined for the present study because this study represents a secondary analysis of data from a yet-to-be published study whose aims/hypothesis required a sample size of $24 \mathrm{VLBW}$ infants.

\section{RESULTS}

The preterm study infants had a mean gestational age of $26.7 \pm$ 1.29 (mean \pm SD) and a corresponding birth weight of $900 \pm$ $254 \mathrm{~g}$. All 27 infants enrolled were ventilated, and all but 3 received $\geq 1$ RBCTx during the first 4 wk of life (mean 3.26 $\pm 1.93)$. The RBCTx volume received by the infants was $49.6 \pm$ $27.3 \mathrm{ml}$ of packed RBCs/kg body wt at the time of RBCTx. All infants had frequent physician-ordered phlebotomies with an average of $54.6 \pm 27.2 \mathrm{ml} / \mathrm{kg}$ of whole blood removed per infant during the first $4 \mathrm{wk}$ of life. None of the 27 infants died and all completed the 28-d study.

The Epo PD parameters $\mathrm{EC}_{50}$ and $E_{\max }$ (equation (1)) were determined for all subjects as previously described (11) (Table 1). The disposition parameters $P_{1}$ and $P_{2}$ characterizing Epo's elimination, which have not been previously reported, were calculated to be $33.2 \mathrm{U} \mathrm{Epo} / \mathrm{ml} / \mathrm{h}$ and $5.99 \mathrm{U}$ Epo/ml, respectively (equation (5)). For these values of $P_{1}$ and $P_{2}$, the clearance values were calculated to be $17.2 \mathrm{ml} / \mathrm{h} \cdot \mathrm{kg}$ for the $500 \mathrm{U} / \mathrm{kg}$ Epo dose, $13.4 \mathrm{ml} / \mathrm{h} \cdot \mathrm{kg}$ for the 1,000 U/ kg Epo dose, and $8.02 \mathrm{ml} / \mathrm{h} \cdot \mathrm{kg}$ for the 2,500 U/kg Epo dose. These calculated clearances are strikingly similar to the clearance values reported as $17.3,13.1$, and $8.20 \mathrm{ml} / \mathrm{h} \cdot \mathrm{kg}$ for Epo doses of 500, 1,000, and 2,500 U/kg, respectively (9).

The dosing optimization simulation procedure determined the best time to administer the twelve $600 \mathrm{U} / \mathrm{kg}$ intravenous (i.v.) bolus unit doses of Epo to all 27 preterm infants (Figure 1). The first two simulated Epo doses corresponded to a double $600 \mathrm{U} /$ $\mathrm{kg}$ Epo dose at birth. The same closeness is observed for the 10th and 11th doses. To maintain infants' simulated $\mathrm{Hb}$ as close as possible to, yet above, the RBCTx target $\mathrm{Hb}$ level, $67 \%$ of Epo doses for all infants were administered in the first $8 \mathrm{~d}$ of life.

The resultant prediction of the plasma Epo concentration profile in infants was determined using the disposition model given by

Table 1. Covariate comparison of good and poor Epo responders for the infant Epo dosing simulations

\begin{tabular}{|c|c|c|c|c|c|}
\hline \multirow[b]{2}{*}{ Factor } & \multicolumn{2}{|c|}{ Good responder ${ }^{\mathrm{a}}$} & \multicolumn{2}{|c|}{ Poor responder } & \multirow[b]{2}{*}{$P$ value } \\
\hline & Mean & SD & Mean & SD & \\
\hline Number of RBCTx & 1.86 & 1.29 & 4.77 & 1.24 & $<0.001$ \\
\hline$E_{\max }(\mathrm{g} /$ day $)$ & 0.918 & 0.327 & 0.597 & 0.348 & $<0.05$ \\
\hline $\mathrm{EC}_{50}(\mathrm{mU} / \mathrm{ml})$ & 78.9 & 75.0 & 131 & 236 & 0.44 \\
\hline$E_{\max } / \mathrm{EC}_{50}$ & 0.0207 & 0.0242 & 0.0224 & 0.0215 & 0.847 \\
\hline $\begin{array}{l}\text { Cumulative whole } \\
\text { blood removed } \\
(\mathrm{ml} / \mathrm{kg})^{\mathrm{b}}\end{array}$ & 36.2 & 19.4 & 74.3 & 19.6 & $<0.001$ \\
\hline
\end{tabular}

$\mathrm{EC}_{50^{\prime}}$ plasma concentration of Epo resulting in half of the maximum $\mathrm{Hb}$ production rate; $E_{\text {max }}$ maximum achievable $\mathrm{Hb}$ production rate; Epo, erythropoietin; $\mathrm{Hb}$, hemoglobin; RBCTx, red blood cell transfusions.

${ }^{\mathrm{a} G o o d}$ responder simulated $\mathrm{Hb}$ stayed above the RBCTx trigger level. Poor responder

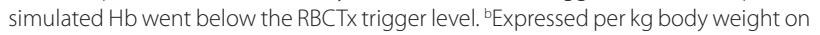
days when phlebotomy occurred. equation (5) (Figure 2). The optimized plasma Epo profile determined the simulated $\mathrm{Hb}$ level (equation (9)) for all 27 infants. Four representative simulated infant $\mathrm{Hb}$ concentration plots are presented in Figure 3. In each simulated $\mathrm{Hb}$ concentration-time plot, weight-adjusted cumulative blood loss and RBCTx Hb trigger criteria derived from the PINT trial are shown. Subjects A and $\mathrm{B}$ are examples of good Epo responders who were predicted to avoid RBCTx, whereas subjects $\mathrm{C}$ and $\mathrm{D}$ were predicted to be poor Epo responders requiring RBCTx. In 13 of the $27(46 \%)$ study subjects, RBCTx were avoided in the simulations.

Results of the simulation study were also used to identify potentially significant clinical and laboratory differences in covariates associated with either good or poor Epo response. To do this and to initiate Epo therapy when it is likely to be the most effective, only covariates that could be determined during the first day of life were compared (i.e., using a two-sample $t$ test).

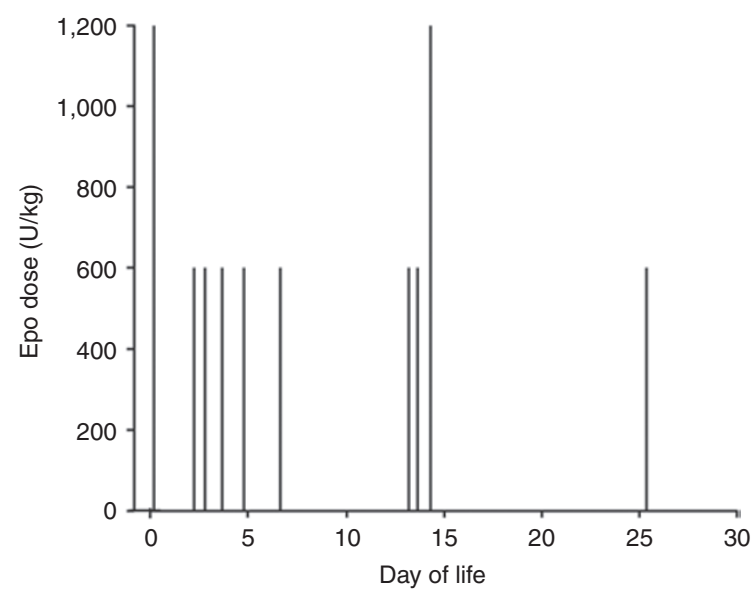

Figure 1. Erythropoietin (Epo) dosing profile. Simulated Epo doses administered to 27 preterm infants optimized to eliminate alloimmune red blood cell transfusions. All simulated Epo doses were $600 \mathrm{U} / \mathrm{kg}$ intravenous bolus doses. The dosing times for the first and second doses were so close as to effectively represent a double dose. The same is the case for the tenth and eleventh doses.

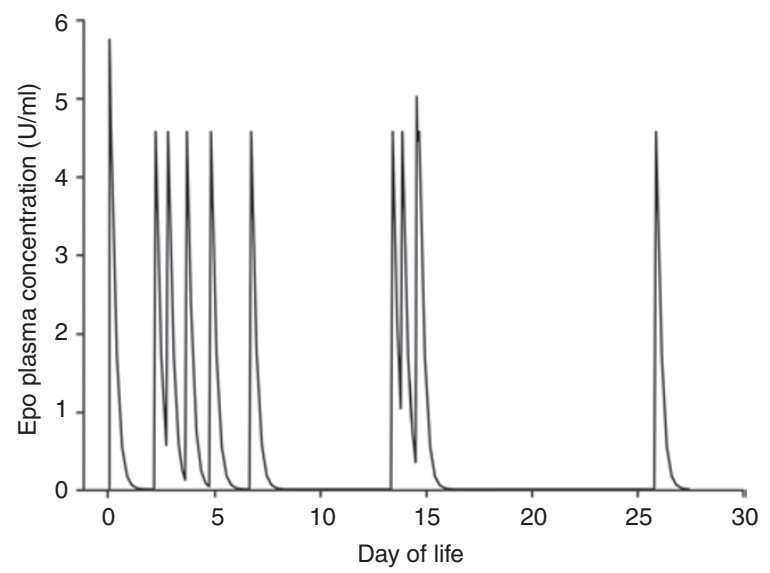

Figure 2. Erythropoietin (Epo) plasma concentration profile. Simulated plasma Epo concentration profile for an infant, corresponding to the simulated, optimized Epo dosing administered to 27 preterm infants shown in Figure 1. The Epo dosing was optimized to avoid red blood cell transfusions in the infants. 


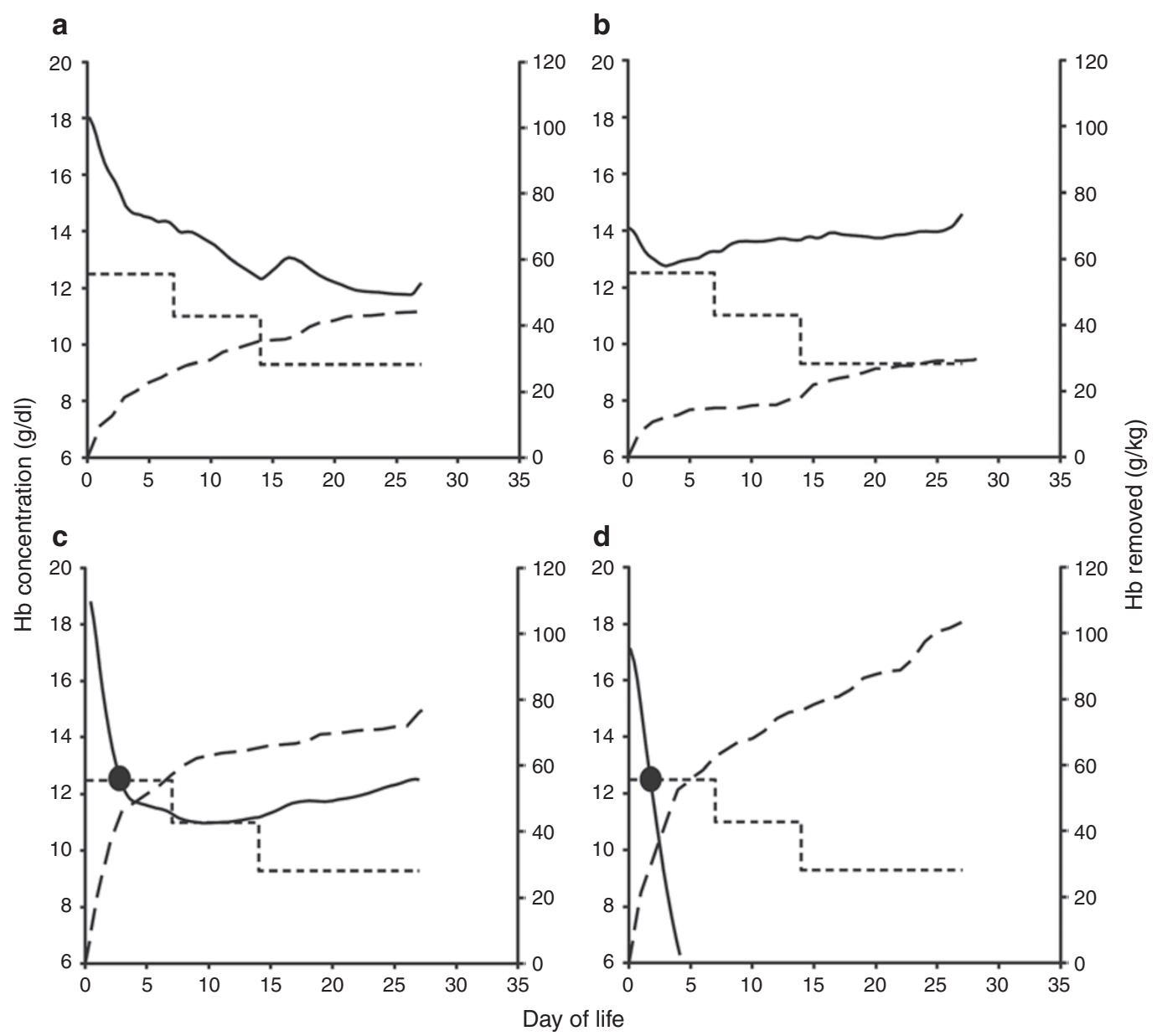

Figure 3. Simulated $\mathrm{Hb}$ profile from erythropoietin (Epo) dosing. Simulated infant $\mathrm{Hb}$ curves based on the optimized Epo dosing shown in Figure 1. Data required to perform these simulations included $\mathrm{Hb}$ concentration at birth, the phlebotomy loss throughout the first $28 \mathrm{~d}$ of life, individual pharmacodynamic parameters, and population pharmacokinetic parameters. The solid line is the infant's simulated $\mathrm{Hb}$, the dashed staircase line is the red blood cell transfusion trigger criteria based on the PINT trial (12), and the dashed increasing line is the cumulative amount of blood removed from the infant as a result of physician-ordered laboratory tests. Subjects $\mathbf{a}$ and $\mathbf{b}$ were "good Epo responders" predicted to avoid transfusions, in contrast to subjects $\mathbf{c}$ and d, who were "poor Epo responders" who would have needed a transfusion at the transfusion trigger crossing point (dark circle).

Because of the small sample size, the analysis was performed in a univariate manner. Five covariates were identified as significant $(P<0.05)$ in distinguishing good responders from poor responders (Table 2). The significant covariate factors identified included the number of RBCTx, $E_{\max }$, and weight-adjusted cumulative blood removed. Covariates analyzed in the first $24 \mathrm{~h}$ of life but not found to be significantly different between good and poor responders were $\mathrm{Hb}$ concentration, Epo concentration, RBC count, white blood cell concentration, mean corpuscular volume, platelet count, reticulocyte count, and heart rate.

\section{DISCUSSION}

Although Epo has been shown to be useful in consistently stimulating erythropoiesis in preterm infants and in significantly reducing the number and volume of RBCTx in some subsets of preterm infants (6), the goal for Epo administration in the present study was to completely eliminate the need for all RBCTx. Results of our PK/PD modeling in 27 VLBW critically ill infants indicated that with optimally simulated Epo dosing, $46 \%$ of infants were predicted to avoid RBCTx as judged by their simulated $\mathrm{Hb}$ levels staying above the RBCTx trigger criteria of the PINT trial (12). This is a higher percentage than the value of $20 \%$ (confidence interval 14-25\%) included as a composite of 16 clinical trials in which Epo was administered to preterm infants per standard dose and schedule without considering individual infant clinical and laboratory characteristics (6). We contend that part of this difference is likely caused by the fact that, in the present study, the simulated Epo dosing was optimized per several characteristics predicting the ability of individual infants to respond or not respond to Epo.

Another reason for the difference may be that the total Epo dose used in the current simulation $(1,800 \mathrm{U} / \mathrm{kg} / \mathrm{wk})$ is relatively high compared with that used in published clinical trials (12). In the 16 clinical trials analyzed for avoidance of RBCTx, only 1 used a higher dose of Epo $(2,100 \mathrm{U} / \mathrm{kg} / \mathrm{wk})$ than the current simulation study (13). This trial also reported that significantly fewer infants in the Epo group needed RBCTx compared with the placebo group (risk ratio $=0.65,95 \%$ confidence interval $[0.46,0.93])$. It is difficult to compare these 16 Epo clinical trials with our simulation study because of heterogeneity as 
Table 2 Comparison of covariates for good and poor Epo responders in optimized Epo dosing simulations for significant covariate factors determined in the first day of life

\begin{tabular}{|c|c|c|c|c|c|}
\hline \multirow[b]{2}{*}{ Factor } & \multicolumn{2}{|c|}{ Good responder } & \multicolumn{2}{|c|}{ Poor responder } & \multirow[b]{2}{*}{$P$ value } \\
\hline & Mean & SD & Mean & SD & \\
\hline Birth weight (kg) & 1.05 & 0.246 & 0.733 & 0.142 & $<0.001$ \\
\hline $\begin{array}{l}\text { Gestational } \\
\text { age (wk) }\end{array}$ & 27.4 & 0.839 & 25.9 & 1.23 & $<0.001$ \\
\hline $\begin{array}{l}\text { Mean corpuscular } \\
\text { hemoglobin (g/dl) }\end{array}$ & 36.1 & 2.98 & 39.0 & 2.90 & $<0.05$ \\
\hline $\begin{array}{l}\text { Phlebotomy loss } \\
\text { day 0-1 ( } \mathrm{ml} / \mathrm{kg})^{\text {a }}\end{array}$ & 6.57 & 2.80 & 12.0 & 4.79 & $<0.001$ \\
\hline $\begin{array}{l}\text { Mean arterial } \\
\text { pressure (torr) }\end{array}$ & 38.7 & 5.56 & 29.6 & 4.91 & $<0.001$ \\
\hline
\end{tabular}

indicated by their inconsistency in Epo dosing, administration routes, and enrollment criteria. In applying the PK/PD model, future analyses could consider alternative RBCTx trigger criteria as more evidence-based RBCTx criteria are identified. This would be easy to implement because the optimization method does not depend on specific RBCTx criteria being applied.

Results of the covariate analysis performed to identify good responders (no RBCTx predicted) and poor responders (predicted need for one or more RBCTx) suggest that several factors may explain the difference between the two groups (Table 2). The $E_{\max }$ parameter was significantly higher for the good-responder group, indicating that, based on our model predictions, these infants can theoretically produce more $\mathrm{Hb}$ in response to given doses of Epo than the lower $E_{\max }$ group. Although the EpoR state in preterm infants has not been directly analyzed, results from our sheep bone marrow ablation study suggest that infants with a higher $E_{\max }$ parameter may have a larger EpoR pool in the bone marrow (14). An additional key parameter found to be significantly different between the good-responder and poorresponder groups was the cumulative weight-adjusted blood removed for laboratory testing. As expected, the cumulative laboratory blood removed in the poor-responder group was much higher than in the good-responder group. Infants with lower body weights become anemic more quickly as a result of their lower blood volume relative to the fixed volumes of blood removed for laboratory testing. The importance of this problem is evident from data showing that anemia in neonates is exacerbated by frequent physician-ordered phlebotomies (2-4).

The current study suggests that large Epo doses should be given in the first week of life for preterm VLBW infants, followed by less frequent, smaller doses. This Epo dosing strategy is in contrast to previous Epo clinical trials that employ a fixed, regular dosing. Another reason why the simulated methodology may prove to be more efficacious than previous clinical trials is that many clinical trials did not start Epo dosing soon enough after birth (15-18), which the present study demonstrated is particularly important.

An additional covariate analysis performed in this study considered covariates that could be determined in the first day of life for the infant (Table 2). Determining covariates at or very close after birth that may predict responsiveness to Epo is especially important because of the need to begin Epo therapy very soon after birth, as demonstrated by our dosing simulations. Although the enrollment criteria for this study included gestational age $\leq 29 \mathrm{wk}$, the infants who responded well to Epo in the simulations had a mean gestation age of $27.4 \mathrm{wk}$, whereas the infants who responded poorly in the simulations to Epo had a mean gestation age of $25.9 \mathrm{wk}$ This is consistent with previous research showing that a preterm infant's average $\mathrm{Hb}$ increases as gestation age increases, therefore making it less likely that they will need to be transfused (19). The other initial covariates that were significantly different between good and poor responders were birth weight, mean arterial pressure, and mean corpuscular hemoglobin. All of these covariates are consistent with a higher gestation age, suggesting that larger, more mature infants are better able to respond to Epo. Because the present study's investigation of covariates predictive of Epo responsiveness did not test all potentially important factors, this remains an important area for future research.

\section{Conclusions}

The present Epo dosing optimization simulation study, based in part on data from actual critically ill anemic premature infants, demonstrates that administration of more frequent doses of Epo in the first week of life likely would prove to be efficacious in eliminating RBCTx needs. The findings also suggest the usefulness of identifying as soon as possible after birth the VLBW infants who will be the best Epo responders in eliminating RBCTx. Accordingly, the results of the current study can serve as the basis for initiating a prospective clinical trial in preterm VLBW infants with specific enrollment criteria and precise Epo dosing. Such a clinical trial will be necessary to confirm the results of the present simulation study.

\section{METHODS}

\section{Subjects}

The study was approved by the University of Iowa Human Subject Internal Review Board in accordance with the Declaration of Helsinki. All parents signed informed consent. The 27 VLBW study infants all had a gestational age $\leq 29 \mathrm{wk}$ and were experiencing respiratory distress severe enough to require ventilation. All infants were cared for in the neonatal intensive care unit at the University of Iowa Children's Hospital and all were treated with expectation of survival. Exclusion criteria included hematological disease (except for anemia associated with phlebotomy loss), alloimmune hemolytic anemia, diffuse intravascular coagulation, emergent RBCTx, or treatment with erythropoiesis-stimulating agents. Subjects were intensively studied during the first $28 \mathrm{~d}$ of life. Results of PD modeling have been published for 14 of the 27 infants (11). During the study period, 12 infants received treatment with 1 to $3 \mathrm{mg} / \mathrm{kg}$ per day of oral iron, whereas 26 infants were treated with caffeine.

Screening for eligible subjects was performed both before and after birth. Of the 152 eligible study subjects during the study period (1/2007 to $10 / 2009), 32$ were enrolled (21\%) and $27(18 \%)$ were studied. The 5 enrolled but not studied were enrolled prior to birth but delivered at $>29$ wk gestation. Those not enrolled but eligible included infants (i) who were unable to be studied because of excessive work load issues $(n=49)$, (ii) who were enrolled in competing studies $(n=36)$, (iii) who were receiving their first transfusion before consent was received $(n=21)$, (iv) who were enrolled before birth but delivered after $>29 \mathrm{wk}$ gestation $(n=33)$, and (v) whose parents did not consent $(n=14)$. 


\section{Study Procedures}

Laboratory, phlebotomy, and RBCTx data were obtained from the subjects' electronic medical records. This permitted the determination of endogenous $\mathrm{Hb}$ production by mass balance principle. Accurate weights for $96.6 \%$ of all discarded blood tests were recorded (11). Leftover plasma was saved for subsequent analysis for Epo. If the plasma volume from the sample was insufficient for these determinations, samples were pooled in 8-h epochs. Endogenous plasma Epo concentrations were determined using a double antibody radioimmunoassay as previously described (20). The leftover anticoagulated blood samples $<3 \mathrm{~d}$ old were analyzed for hematological parameters using a Sysmex XE-2100 automatic hematology analyzer (Sysmex, Kobe, Japan).

\section{Simulation and PD}

The infant Epo dosing simulations were designed to examine whether repeated $600 \mathrm{U} / \mathrm{kg}$ i.v. Epo doses administered at optimal times could completely eliminate the need for RBCTx. The simulated optimized Epo dosing regimen was designed to provide 12 i.v. bolus doses during the first $28 \mathrm{~d}$ of life. This number of "unit doses" was chosen to correspond to the approximate number and amount of Epo doses commonly administered to preterm infants in clinical trials (6).

The RBCTx triggers were defined by a modification of criteria applied to preterm VLBW infants in the largest randomized clinical RBCTx trial to date (i.e., the Preterm Infants in Need of Transfusion (PINT) study) (12). For simplicity, the average Hb levels for infants requiring respiratory support in the restricted and liberal study arms were used. This resulted in the following postnatal age-based $\mathrm{Hb}$ trigger levels: wk 1: $12.5 \mathrm{~g} / \mathrm{dl}$, wk 2: $11 \mathrm{~g} / \mathrm{dl}$, wk 3 and beyond: $9.3 \mathrm{~g} / \mathrm{dl}$. In the PK/PD simulation model applied, Epo optimization was considered successful if Epo dosing was able to maintain the infant's Hb level above the PINT study RBCTx trigger.

\section{PK/PD Model Used in Simulations}

To determine the rate of $\mathrm{Hb}$ production from the simulated Epo dosing regimen, the following model was used to estimate the effect of Epo dosing in individual infants based on its concentration at any given point in time:

$$
E(t)=\frac{E_{\text {max }} \times \operatorname{Epo}\left(t-t_{\text {lag }}\right)}{\mathrm{EC}_{50}+\operatorname{Epo}\left(t-t_{\text {lag }}\right)}
$$

where $\mathrm{E}(\mathrm{t})$ is the $\mathrm{Hb}$ production rate at time $t$; $t_{\mathrm{lag}}$ is the lag time between the Epo stimulation of EpoR and the appearance of newly synthesized reticulocytes (i.e., $\mathrm{Hb}$ appearing in the circulation); $\mathrm{EC}_{50}$ is the plasma concentration of Epo resulting in half of the maximum $\mathrm{Hb}$ production rate; and $E_{\text {max }}$ is the maximum achievable $\mathrm{Hb}$ production rate.

$\mathrm{The} \mathrm{Hb}$ level of individual infants at birth was used as the initial $\mathrm{Hb}$ level in the simulations. To account for RBC production, $\mathrm{RBC}$ senescence and $\mathrm{Hb}$ loss resulting from laboratory blood testing in the simulations, each infant's $\mathrm{Hb}$ concentration over the study period was modeled as follows:

$$
\begin{aligned}
& \frac{\mathrm{dHb}(t)}{\mathrm{d} t}=\mathrm{E}(t)-\mathrm{Hb}(t) \times \mathrm{Cl}_{\mathrm{p}}(t)-\frac{\mathrm{Hb}_{\mathrm{O}}(t)}{\tau-t} \\
& \frac{\mathrm{dHb}_{\mathrm{O}}(t)}{\mathrm{d} t}=-\mathrm{Hb}_{\mathrm{O}}(t) \times \mathrm{Cl}_{P}(t)-\frac{\mathrm{Hb}_{\mathrm{O}}(t)}{\tau-t}
\end{aligned}
$$

with initial conditions where

$$
\mathrm{Hb}(0)=\mathrm{Hb}_{\mathrm{O}}(0)=\mathrm{Hb}_{\mathrm{ss}}
$$

and

$$
C_{\mathrm{Hb}}(0)=\frac{\mathrm{Hb}(0)}{V_{\mathrm{KG}} \times W(0)} \times s
$$

The phlebotomy clearance function, $\mathrm{Cl}_{\mathrm{p}}(t)$, is the volume of blood removed/time/blood volume; $\mathrm{Hb}_{\mathrm{O}}(t)$ is the old $\mathrm{Hb}$ amount remaining at time $t$ (i.e., the $\mathrm{Hb}$ remaining from the $\mathrm{RBCs}$ present at birth); $\mathrm{Hb}(t)$ is the total amount of $\mathrm{Hb}$ at time $t$ (remaining old plus newly produced $\mathrm{Hb}$ ); $\mathrm{Hb}_{\text {ss }}$ is the $\mathrm{Hb}$ amount at steady state; $\tau$ is the life span of RBCs; $V_{\mathrm{KG}}$ is the blood volume per $\mathrm{kg} ; W(0)$ is the weight of the infant at birth; and $C_{\mathrm{Hb}}(t)$ is the concentration of $\mathrm{Hb}$ at time $t$.

The model equations above assume that newly produced neonatal RBCs do not undergo senescence during the 28-d study period because the RBC life span is greater than $28 \mathrm{~d}$. In the model simulations, it was assumed that newly produced RBCs had a fixed life span, $\tau$ at $65.8 \mathrm{~d}$ (11). There was no need to considerer RBC life spans other than the endogenous RBC life spans because the ultimate aim for the simulation study was to eliminate RBCTx; therefore, RBCTx were not simulated.

\section{Epo PK}

Information about the elimination of Epo (PK) in preterm infants is required to derive Epo dosing simulations. A previous study in preterm infants by Juul et al. reported Epo plasma clearance values of $17.3,13.1$, and $8.20 \mathrm{ml} / \mathrm{h} \cdot \mathrm{kg}$ with exogenous Epo doses of 500 , 1,000 , and $2,500 \mathrm{U} / \mathrm{kg}$, respectively (9). The $500 \mathrm{U} / \mathrm{kg}$ clearance value was similar to the value of $16 \mathrm{ml} / \mathrm{h} \cdot \mathrm{kg}$ determined previously by our group (5). The study by Juul et al. reported a volume of distribution of $104 \mathrm{ml} / \mathrm{kg}$ that did not change with Epo dose administered. The disposition elimination of Epo in the simulation model was estimated as follows:

$$
\frac{\mathrm{dEPO}}{\mathrm{d} t}=-\frac{P_{1} \times \mathrm{EPO}}{P_{2}+\mathrm{EPO}}
$$

where

$$
\begin{aligned}
& \mathrm{EPO}_{1}(0)=500 / V \\
& \mathrm{EPO}_{2}(0)=1,000 / V \\
& \mathrm{EPO}_{3}(0)=2,500 / V
\end{aligned}
$$

In equation (5), EPO is the plasma Epo concentration at time $t ; P_{1}$ and $P_{2}$ are disposition parameters, where $P_{1}$ is the maximum rate at which the Epo concentration declines and $P$ is the plasma Epo concentration at which Epo is eliminated at half of the maximum rate; and $V$ is the fixed volume of distribution of Epo, i.e., $104 \mathrm{ml} / \mathrm{kg}(9)$.

For each literature reported Epo dose (i.e., 500, 1,000, and 2,500 U/kg) and fixed $P_{1}$ and $P_{2}$ disposition values, an area under the curve (AUC) can be calculated according to the integration from time 0 to infinity for equation (5). Therefore, for each Epo dose, corresponding to the current $P_{1}$ and $P_{2}$ parameter estimates, an AUC and clearance value can be calculated according to

$$
\begin{aligned}
& \text { Dose }_{1} / \mathrm{AUC}_{1}=\mathrm{CL}_{1, C} \\
& \text { Dose }_{2} / \mathrm{AUC}_{2}=\mathrm{CL}_{2, C} \\
& \text { Dose }_{3} / \mathrm{AUC}_{3}=\mathrm{CL}_{3, C}
\end{aligned}
$$

where AUC is the area under the curve calculated for the given Epo dose and $\mathrm{CL}_{\mathrm{C}}$ is the plasma clearance calculated for the same dose. The values of $P_{1}$ and $P_{2}$ were estimated such that the difference between the calculated and literature-derived Epo clearance values was minimized by minimizing the value of the objective function as follows:

Objective function $=\left(\mathrm{CL}_{1, C}-\mathrm{CL}_{1, R}\right)-\left(\mathrm{CL}_{2, C}-\mathrm{CL}_{2, R}\right)-\left(\mathrm{CL}_{3, C}-\mathrm{CL}_{3, R}\right)(8)$

The notation $\mathrm{CL}_{1 \mathrm{R}}$ is the reported clearance for dose 1 (e.g., $17.3 \mathrm{ml} / \mathrm{h} \cdot \mathrm{kg}$ for a $500 \mathrm{U} / \mathrm{kg}$ dose of Epo) (9). The objective function value for equation (8) was minimized using the derivative free optimization algorithm developed by Nelder and Mead (21) referred to as the simplex method. With the combined PK information derived from Juul et al. and given in equation (5) and the PD information determined from equation (1), the final model applied in the Epo dosing simulations for individual study infants was 


\section{Erythropoietin dosing in preterm infants}

$$
\begin{aligned}
& \frac{\mathrm{dHb}(t)}{\mathrm{d} t}=\frac{E_{\text {max }} \times \mathrm{EPO}\left(t-t_{\text {lag }}\right)}{\mathrm{EC}_{50}+\mathrm{EPO}\left(t-t_{\text {lag }}\right)}-\mathrm{Hb}(t) \times \mathrm{Cl}_{p}(t)-\frac{\mathrm{Hb}_{\mathrm{o}}(t)}{\tau-t} \\
& \frac{\mathrm{dHb}_{\mathrm{o}}(t)}{\mathrm{d} t}=-\mathrm{Hb}_{\mathrm{o}}(t) \times \mathrm{Cl}_{p}(t)-\frac{\mathrm{Hb}_{\mathrm{o}}(t)}{\tau-t} \\
& \frac{\mathrm{dEPO}}{\mathrm{d} t}=-\frac{P_{1} \times \mathrm{EPO}}{P_{2}+\mathrm{EPO}}
\end{aligned}
$$

with initial conditions

$$
\begin{aligned}
& \mathrm{Hb}(0)=\mathrm{Hb}_{\mathrm{O}}(0) \\
& \mathrm{Hb}_{\mathrm{O}}(0)=\mathrm{E}_{S S} \times \tau \\
& \mathrm{EPO}(0)=\text { Dose } / V
\end{aligned}
$$

where $\mathrm{E}_{\mathrm{ss}}$ is the $\mathrm{Hb}$ production rate at birth. The final model given by equation 9 was used to simulate changes in hemoglobin for individual infants based on the plasma Epo concentration, phlebotomy blood loss, and endogenous RBC senescence.

\section{Dosing Optimization Algorithm}

Optimal Epo dosing was defined as the dosing schedule, which results in a $\mathrm{Hb}$ concentration vs. time curve that is as close as possible tobut always remains above-the Hb level defining the RBCTx trigger. Accordingly, the $\mathrm{Hb}$ target level used in the simulation model, $R(t)$, was $3 \mathrm{~g} / \mathrm{dl}$ above the $\mathrm{Hb}$ level defined by a linear spline equal to the aforementioned PINT-derived RBCTx trigger $\mathrm{Hb}$ level (12). The $3 \mathrm{~g} /$ $\mathrm{dl} \mathrm{Hb}$ margin was empirically chosen to reduce the likelihood of $\mathrm{Hb}$ concentrations falling below the PINT RBCTx trigger. This margin is required because of the natural smoothness of the simulated $\mathrm{Hb}$ level, which is otherwise impossible to achieve given the staircase-shape RBCTx trigger level. The simulated $\mathrm{Hb}$ and Epo levels were determined according to equation (9), whereas the objective function to be minimized was

$$
\text { Objective function }=\sum_{i=1}^{N} \int_{0}^{E}\left(S_{\mathrm{HB}, i}(t)-R_{i}(t)\right)^{2} \mathrm{~d} t
$$

, where $i$ denotes the individual subject; $N$ is the number of subjects ( $N=27$ subjects); $E$ is the duration of the study (i.e., $28 \mathrm{~d}$ ); $S_{\mathrm{HB}, \mathrm{i}}(t)$ is the simulated $\mathrm{Hb}$ profile for subject $i$ at time $t$; and $R_{\mathrm{i}}(\mathrm{t})$ is the target $\mathrm{Hb}$ profile at time $t$ for subject $i$. The value of objective function (equation (11)) was again minimized by the Nelder-Mead simplex method (21). Equation 11 permits the determination of individual Epo dosing regimens for all 27 infants that maintains simulated $\mathrm{Hb}$ concentrations as close as possible to the RBCTx target $\mathrm{Hb}$. The double precision Fortran subroutine RETARD was used for numerical integration of the delaytype differential equations. The $\mathrm{Cl}_{\mathrm{p}}$ parameter was represented as a linear spline fit of the infants' phlebotomy data. All graphical output was constructed using WINFUNFIT, a Windows version evolved from the general nonlinear regression program FUNFIT (22).

The sample size was not specifically determined because the present study represents a secondary analysis of a yet-to-be published study in which the sample size was 24 VLBW infants.

\section{ACKNOWLEDGMENTS}

The rabbit Epo antiserum used in the Epo radioimmunoassay was a gift from Gisela K. Clemens. We appreciate all of the hard work by our laboratory team: Robert Schmidt, Demet Nalbant, Earl Gingerich, and Jessica Goehring, and research nursing coordinator Gretchen Cress and the team of neonatal research nurses. We are especially thankful for the advice and suggestions of Ronald G. Strauss on improving the manuscript and for the support from Sysmex America, Inc., for the loan of the Sysmex XE-2100 automatic hematology analyzer (Sysmex Corporation, Kobe, Japan).

\section{STATEMENT OF FINANCIAL SUPPORT}

This study was supported by National Institutes of Health US Public Health Service, grant 2 P01-HL046925, and by the Children's Miracle Network Telethon of lowa.

\section{REFERENCES}

1. Widness JA. Pathophysiology of anemia during the neonatal period, including anemia of prematurity. Neoreviews 2008;9:e520.

2. Strauss RG. Red blood cell transfusion practices in the neonate. Clin Perinatol 1995;22:641-55

3. Widness JA, Madan A, Grindeanu LA, Zimmerman MB, Wong DK, Stevenson DK. Reduction in red blood cell transfusions among preterm infants: results of a randomized trial with an in-line blood gas and chemistry monitor. Pediatrics 2005;115:1299-306.

4. Madan A, Kumar R, Adams MM, Benitz WE, Geaghan SM, Widness JA. Reduction in red blood cell transfusions using a bedside analyzer in extremely low birth weight infants. J Perinatol 2005;25:21-5.

5. Widness JA, Veng-Pedersen P, Peters C, Pereira LM, Schmidt RL, Lowe LS. Erythropoietin pharmacokinetics in premature infants: developmental, nonlinearity, and treatment effects. J Appl Physiol 1996;80:140-8.

6. Ohlsson A, Aher SM. Early erythropoietin for preventing red blood cell transfusion in preterm and/or low birth weight infants. Cochrane Database Syst Rev 2006;3:CD004863.

7. Veng-Pedersen P, Widness JA, Pereira LM, Peters C, Schmidt RL, Lowe LS Kinetic evaluation of nonlinear drug elimination by a disposition decomposition analysis. Application to the analysis of the nonlinear elimination kinetics of erythropoietin in adult humans. J Pharm Sci 1995;84:760-7.

8. Veng-Pedersen P, Widness JA, Pereira LM, Schmidt RL, Lowe LS. A comparison of nonlinear pharmacokinetics of erythropoietin in sheep and humans. Biopharm Drug Dispos 1999;20:217-23.

9. Juul SE, McPherson RJ, Bauer LA, Ledbetter KJ, Gleason CA, Mayock DE. A phase I/II trial of high-dose erythropoietin in extremely low birth weight infants: pharmacokinetics and safety. Pediatrics 2008;122:383-91.

10. Sawyer ST, Krantz SB, Goldwasser E. Binding and receptor-mediated endocytosis of erythropoietin in Friend virus-infected erythroid cells. J Biol Chem 1987;262:5554-62.

11. Freise KJ, Widness JA, Veng-Pedersen P. Erythropoietic response to endogenous erythropoietin in premature very low birth weight infants. J Pharmacol Exp Ther 2010;332:229-37.

12. Kirpalani H, Whyte RK, Andersen C, et al. The Premature Infants in Need of Transfusion (PINT) study: a randomized, controlled trial of a restrictive (low) versus liberal (high) transfusion threshold for extremely low birth weight infants. J Pediatr 2006;149:301-7.

13. Haiden N, Cardona F, Schwindt J, et al. Changes in thrombopoiesis and platelet reactivity in extremely low birth weight infants undergoing erythropoietin therapy for treatment of anaemia of prematurity. Thromb Haemost 2005;93:118-23.

14. Veng-Pedersen P, Chapel S, Al-Huniti NH, et al. Pharmacokinetic tracer kinetics analysis of changes in erythropoietin receptor population in phlebotomy-induced anemia and bone marrow ablation. Biopharm Drug Dispos 2004;25:149-56.

15. Arif B, Ferhan K. Recombinant human erythropoietin therapy in lowbirthweight preterm infants: a prospective controlled study. Pediatr Int 2005; 47:67-71.

16. Avent M, Cory BJ, Galpin J, et al. A comparison of high versus low dose recombinant human erythropoietin versus blood transfusion in the management of anaemia of prematurity in a developing country. J Trop Pediatr 2002;48:227-33.

17. Salvadó A, Ramolfo P, Escobar M, et al. [Early erythropoietin use for the prevention of anemia in infant premature]. Rev Med Chil 2000;128:1313-7.

18. Romagnoli C, Zecca E, Gallini F, Girlando P, Zuppa AA. Do recombinant human erythropoietin and iron supplementation increase the risk of retinopathy of prematurity? Eur J Pediatr 2000;159:627-8.

19. Jopling J, Henry E, Wiedmeier SE, Christensen RD. Reference ranges for hematocrit and blood hemoglobin concentration during the neonatal period: data from a multihospital health care system. Pediatrics 2009;123:e333-7.

20. Georgieff MK, Amarnath UM, Landon MB, Mills MM, Ophoven JC. Newborn iron status of infants of diabetic mothers (Idms). Clinical Research 1998;36:224-224.

21. Nelder JA, Mead R. A simplex-method for function minimization. Computer Journal 1965 7:308-313.

22. Veng-Pedersen P. Curve fitting and modeling in pharmacokinetics and some practical experiences with NONLIN and a new program FUNFIT. J Pharmacokinet Biopharm 1977 5:513-531. 